\title{
Circulation statistics and climate change in Central Europe: PRUDENCE simulations and observations
}

\author{
Aad van Ulden • Geert Lenderink • Bart van den Hurk • \\ Erik van Meijgaard
}

Received: 15 February 2005 / Accepted: 17 October 2006 / Published online: 17 March 2007

(C) Springer Science + Business Media B.V. 2007

\begin{abstract}
PRUDENCE simulations of the climate in Central Europe are analysed with respect to mean temperature, mean precipitation and three monthly mean geostrophic circulation indices. The three global models show important circulation biases in the control climate, in particular in the strength of the west-circulations in winter and summer. The nine regional models inherit much of the circulation biases from their host model, especially in winter. In summer, the regional models show a larger spread in circulation statistics, depending on nesting procedures and other model characteristics. Simulated circulation biases appear to have a significant inluence on simulated temperature and precipitation. The PRUDENCE ensemble appears to be biased towards warmer and wetter than observed circulations in winter, and towards warmer and dryer circulations in summer. A2-scenario simulations show important circulation changes, which have a significant impact on changes in the distributions of monthly mean temperature and precipitation. It is likely that interactions between land-surface processes and atmospheric circulation play an important role in the simulated changes in the summer climate in Central Europe.
\end{abstract}

\section{Introduction}

The climate in Europe is strongly influenced by the statistics of the atmospheric circulation. Westerly flows bring mild, rainy weather in winter and cool, rainy weather in summer. Easterly flows account for dry, cold weather in winter and dry, warm weather in summer. Therefore climate models should simulate realistic circulation statistics in order to be credible (Turnpenny et al. 2002; Van Oldenborgh and Van Ulden 2003; Jylhä et al. 2004; Van Ulden and Van Oldenborgh 2006). If a model is biased in its circulation simulations, this is likely to have an impact on the quality of simulations of other variables like temperature and precipitation. In climate change simulations, circulation may play a role as well if the circulations change as a result of new radiative forcing conditions (Räisänen et al. 2004; Van Ulden and Van Oldenborgh 2006).

A. van Ulden $(\bowtie) \cdot$ G. Lenderink $\cdot$ B. van den Hurk $\cdot$ E. van Meijgaard Royal Netherlands Meteorological Institute (KNMI), De Bilt, The Netherlands e-mail: aad.van.ulden@knmi.nl 
In this paper we will analyse climate simulations by three global models and nine high resolution regional models, carried out in the PRUDENCE-project (Christensen et al. 2002). We will assess simulated atmospheric circulations using geostrophic circulation indices derived from monthly mean sea level pressure fields in Central Europe. We will also analyse simulations of monthly mean temperature and precipitation in Germany and their relation to atmospheric circulation. In Section 2 we list analysis domains, observations and models. In Section 3, we compare circulation indices based on simulations by three global models with the statistics of circulation indices based on analysed pressure fields. In Section 4, correlations between nine regional models and the driving global atmosphere model HadAM3H are discussed. In Section 5, control simulations of circulation indices are compared with observed indices. In Section 6, we present changes in the simulated circulations between the control runs and the A2-scenario runs. In Section 7 we present control simulations and A2-scenario simulations of temperature and precipitation for Germany and compare these with observations. In Section 8 we discuss changes in the distributions of temperature, precipitation and circulation in more detail. In Section 9 we present our conclusions.

\section{Analysis domains, observations and models}

\subsection{Analysis domains and definition of variables}

The analysis domains, used in this study, are shown in Fig. 1. The state of the monthly mean atmospheric circulation in Central Europe was analysed in the domain $45^{\circ}-55^{\circ} \mathrm{N}$, $0^{\circ}-20^{\circ} \mathrm{E}$. We used the mean sea level pressure at the four corners of this domain and the central pressure $\mathrm{P}_{\mathrm{C}}$ in $50^{\circ} \mathrm{N}, 10^{\circ} \mathrm{E}$. All five pressure locations are away from major mountains, so orography is not likely to have an important influence on the analysis. We

Fig. 1 Analysis domains in Central Europe. The five dots give the locations used to compute the geostrophic flow indices. The small rectangle is the domain used for temperature and precipitation

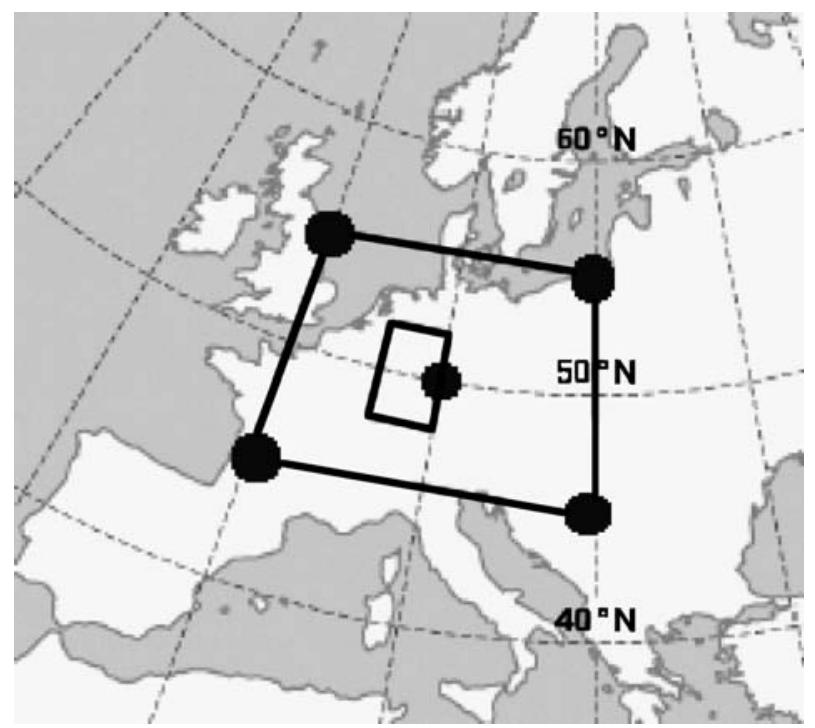


computed three circulation indices from the five pressures. The mean geostrophic wind components $G$-west and $G$-south, which correspond to westerly flows and southerly flows respectively, were computed from the pressures at the four corners of the domain, using a fixed value of $1.2 \mathrm{~kg} / \mathrm{m}^{3}$ for the air density and a value of $0.000112 \mathrm{~s}^{-1}$ for the Coriolisparameter at $50^{\circ} \mathrm{N}$. The third index was the geostrophic vorticity. As a simple proxy for the geostrophic vorticity we used the difference between the mean pressure at the four corners of the domain and the central pressure $\mathrm{P}_{\mathrm{C}}$.

Monthly mean temperature and precipitation were analysed as area averages in the domain $48^{\circ}-52^{\circ} \mathrm{N}, 6^{\circ}-10^{\circ} \mathrm{E}$. This domain roughly corresponds to the river Rhine catchment between the German borders with Switzerland and the Netherlands.

\subsection{Observations}

For the validation of the model simulations we used the following data sets:

Monthly mean sea level pressure: ADVICE-analysis (Jones et al. 1999). This analysis has a spatial resolution of $5^{\circ} \times 10^{\circ}$ and covers the period $1780-1995$. This long analysis period allowed an assessment of climate variations for different $30 \mathrm{yr}$ periods.

NCAR-analysis (Trenberth and Paolino 1980). Resolution: $5^{\circ} \times 5^{\circ}$. Period: 1901-2000.

ERA-40 re-analysis (Kållberg et al. 2004). Resolution: $2.5^{\circ} \times 2.5^{\circ}$. Period: 1959-2000.

We compared the circulation indices computed from these pressure data sets for the overlapping time period and found a very good agreement. For the geostrophic vorticity, we found a modest impact of resolution differences on the interannual variability, as given by the monthly standard deviations. Compared with the ERA-40 data, this standard deviation was about $20 \%$ smaller for the ADVICE resolution and about $10 \%$ smaller for the NCAR resolution. For the other indices we found no impact of the resolution.

Monthly mean temperature: CRU2 analysis (New et al. 2000). Resolution $0.5^{\circ}$. Period: 1901-2000. Data averaged over the domain $48^{\circ}-52^{\circ} \mathrm{N}, 6^{\circ}-10^{\circ} \mathrm{E}$.

Monthly mean precipitation: Analysis by Hydrological Rhine Committee (Van den Hurk et al. 2005). Resolution; sub-catchment scale. Period: 1961-1995. Data averaged over the German part of the Rhine catchment.

\subsection{Model simulations}

We will analyse monthly mean control simulations (1961-1990) and A2-scenario simulations (2071-2100) by three global models and nine regional models. The global models were: HadAM3H, ECHAM4 and ARPEGE. The regional models were: CHRM, CLMsn, HadRM3H, HIRHAM, RACMO2, RCAO, RegCM3, REMO and PROMES. We analysed only regional simulations using boundary conditions from HadAM3H and SSTchanges computed by HadCM3. RCAO and RACMO2 used for the Baltic Sea changes in SST from a high resolution Baltic Sea model. For RACMO2 we analysed a run using boundary conditions from ERA-40 as well, as an intermediate step between observations and the control simulations (Lenderink et al. 2003).

A general description of the models and further references can be found in Jacob et al. (2007), Déqué et al. (2007) and Christensen and Christensen (2007). 


\section{Control simulations by three global models compared with observations}

In Fig. 2, we show the control simulations of $30 \mathrm{y}$ mean circulation indices by the three global models and the observed indices. We also illustrate the variability in the observations by showing for each month the maximum and minimum value of the $30 \mathrm{y}$ running mean, for the period 1780-1995. We see that $G$-west is poorly simulated by ARPEGE. This model has a very strong westerly bias in winter and a clear easterly bias in summer. The winter bias of HadAM3H and ECHAM4 is more modest, but still outside the observed range.

Fig. 2 Control simulations of circulation indices by the three global PRUDENCE models compared with observations. The range of natural variability was obtained by computing the $30 \mathrm{y}$ running mean for each month and by taking the maximum and minimum value of these running means over the period 1780-2000
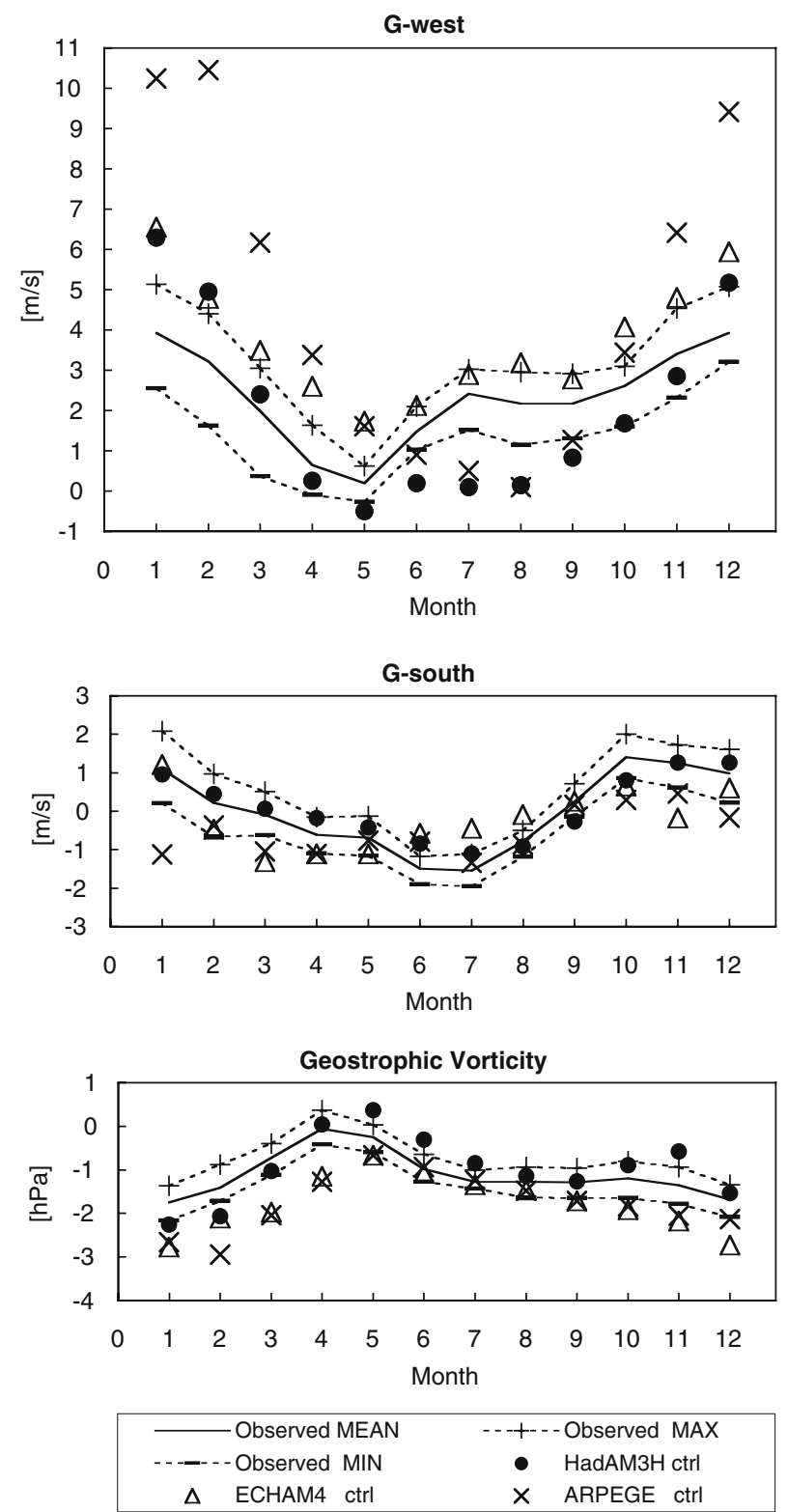
HadAM3H has a pronounced easterly bias in summer. G-south is fairly well simulated by the models, The geostrophic vorticity is mainly negative (anticyclonic circulations) and fairly well simulated by HadAM3H. ECHAM4 and ARPEGE show a pronounced anticyclonic bias in winter and spring.

Of all the biases, those in $G$-west were probably the most important, because this index determines the degree of continentality of the climate in Central Europe. This index is highly correlated with NAO in the winter half year. Visual inspection of simulated and observed pressure fields showed that the positive winter bias in G-west in Central Europe is part of a large scale bias in the circulation pattern over the North Atlantic and Europe (Jones et al. 2001). Also the easterly summer bias in the HadAM3H simulation is part of a large scale pressure bias, with lower than observed pressures in Southern Europe and the Middle East (Jones et al. 2001). Such large-scale circulation biases are common in global climate model simulations (D'Andrea et al. 1998) and also present in simulations by many recent global coupled climate models (Van Ulden and Van Oldenborgh 2006).

\section{Correlations of regional model circulations with those of HadAM3H}

As a test on the correspondence between the circulations simulated by the driving global model and by the regional models we computed for each month the correlations $\left(\mathrm{r}^{2}\right)$ between $G$-west simulated by HadAM3H and those of the regional models. These are shown in Fig. 3 for the control runs. We see in general high correlations in winter which is due to strong dynamical boundary forcings in winter. In summer the regional models differ greatly from each other in their correlation with HadAM3H. CLMsn and RACMO2 show the highest correlations. This is probably related to the different relaxation techniques employed by these models. CLMsn uses spectral nudging for momentum, which ensures that the large-scale dynamic systems follow similar developments as those produced by the driving global model. In RACMO2 a relatively wide relaxation zone for momentum is used, which has a similar impact as spectral nudging. Differences in domain size may lead to differences in correlations as well. HIRHAM shows in general the lowest correlations with HadAM3H. Apparently the dynamic boundary forcing is weak in this model.

\section{Regional control simulations of the circulation compared with ERA-40}

Models with a low correlation with HadAM3H do not necessarily produce a different (better or worse) climate. In Fig. 4 we show the mean circulation differences with ERA-40

Fig. 3 Correlations between the monthly mean control simulations of G-west by the nine nested regional models with those of the driving global model HadAM3H

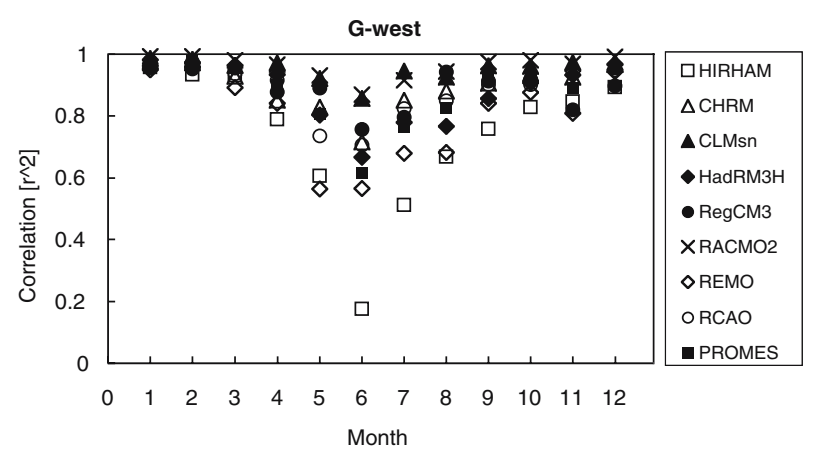

Springer 
Fig. 4 Difference between the $30 \mathrm{y}$ mean control simulations of G-west and those from ERA-40

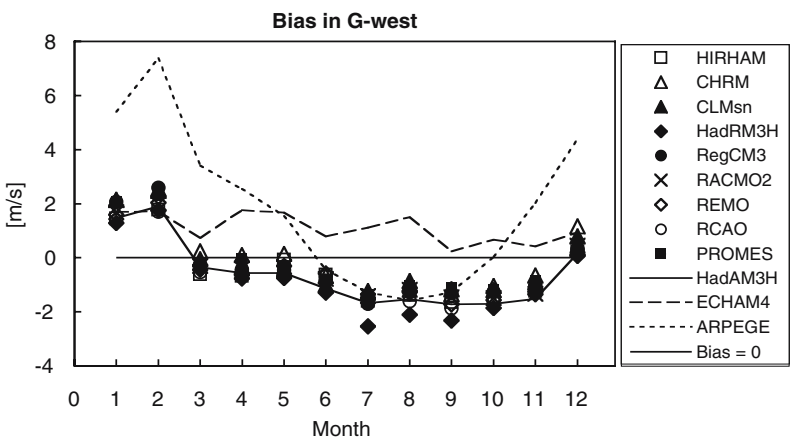

for the control runs of the regional models. For comparison the global models are included as well. We see that in general the mean circulation climate of the regional models stays fairly close to that of $\operatorname{HadAM} 3 \mathrm{H}$, and shows similar biases. There are, however, some interesting deviations. Many models have a more westerly and more anticyclonic flow than HadAM3H, but the difference is modest. HadRM3H has a more pronounced easterly bias in summer than the other regional models. This summer bias is also stronger than for HadAM3H. This is remarkable, because these models are regional and global versions of the same model. In general however, the circulation differences between the global models are larger than the differences between the regional models and the driving global model.

Next we consider the interannual variability of the circulation as given by the $30 \mathrm{y}$ standard deviation for each month. From the long observation record (Jones et al. 1999) it appeared that the $30 \mathrm{y}$ running standard deviations varied significantly in time. We found a range of about $\pm 30 \%$ in the period $1780-1995$. Considering this range of natural variability, the regional models give a fair representation of the interannual variability of the circulation, and the mean circulation bias seems to be a more important shortcoming of the climate simulations than biases in the interannual variability.

\section{Changes in the circulation from control simulations to A2-scenario}

In Fig. 5 we show the changes in the mean circulation indices between the A2-runs and the control simulations. In winter, the regional models closely follow the circulation changes simulated by the driving global model HadAM3H, i.e. almost no change in geostrophic vorticity, a weak enhancement of southerly flows, and a clear enhancement of the strength of westerly flows. This response contrasts with that simulated by ECHAM4 which shows a clear enhancement of northwesterly flows. This difference in circulation response was also noted by Räisänen et al. (2004).

In summer the circulation response of the global models is more similar than in winter. Most prominent is a weakening of westerlies, in particular in August. It is related to pressure increases over the British Isles (Räisänen et al. 2004). This weakening of westerly flow is less pronounced in some regional models. In spring and autumn, the global models produce rather different responses, in particular in $G$-west. The causes of such differences in circulation response are unclear. It appears for example that the response of global coupled climate models to radiative forcings is quite sensitive to differences in physical parameterisations (Thorpe 2005). More research is needed to clarify this complex issue. 
Fig. 5 Changes in 30 y mean circulation indices from control simulations to A2-scenario simulations
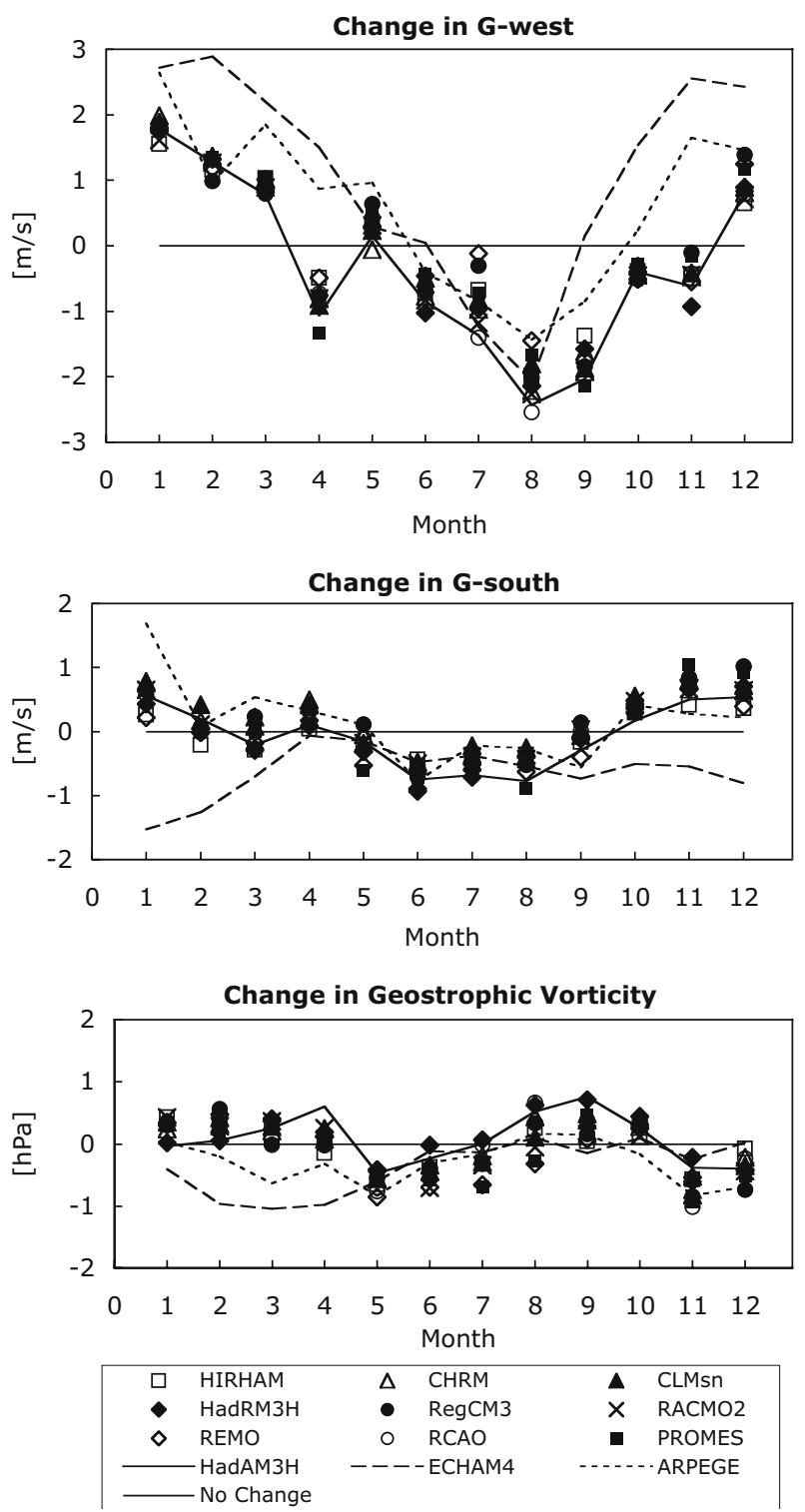

\section{Simulations of mean temperature and precipitation by two regional models}

In this section we present simulations and observations of temperature and precipitation for the domain $48^{\circ}-52^{\circ} \mathrm{N}, 6^{\circ}-10^{\circ} \mathrm{E}$. We use the period $1961-1990$ for the observations (see Section 2). Model simulations by HadRM3H and RACMO2 are presented as examples. HadRM3H was selected because this model is quite sensitive to summer drying (Lenderink et al. 2007) and has the most pronounced warm bias in the control simulations in summer, compared with the other regional models in the PRUDENCE ensemble (Jacob et al. 2007). 
Moreover, HadRM3H has the strongest easterly flow bias in the control simulations in summer. RACMO2 is relatively realistic with respect to summer drying (Lenderink et al. 2007), and has a less pronounced easterly flow bias. For this model we have performed simulations using ERA-40 boundary conditions for the period 1961-1990, in addition to the simulations using boundary conditions from HadAM3H. The RACMO2-ERA simulations provide an important intermediate between observations and climate simulations, allowing to isolate artefacts from the regional model and artefacts due to differences in the boundary conditions. In Fig. 6 we show the observations and model simulations of mean temperature and mean precipitation. We see that RACMO2-ERA reproduces the observed temperature and precipitation quite well for all months of the year. Also the control run by RACMO2 compares well with observations, except in winter when there is a warm and wet bias. The control run by HadRM3H shows similar biases in winter, but in addition a warm bias in July and August. The A2-scenario simulations show similar changes in winter for the two models: it gets warmer and wetter (not shown). In summer however, the two models produce very different changes. HadRM3H shows a much stronger warming and drying than RACMO2. The temperatures and precipitation simulated

Fig. 6 Simulations and observations of $30 \mathrm{y}$ mean temperature deviations and precipitation. Note that the observed temperature anomalies vanish by definition

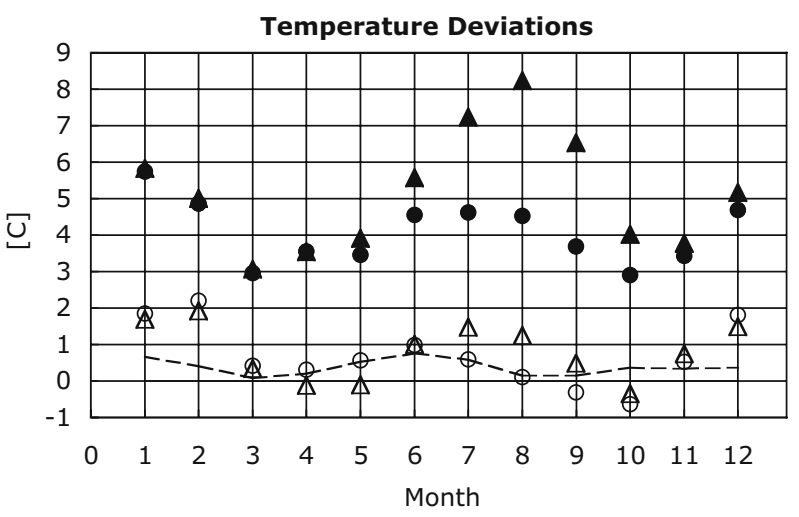

Precipitation

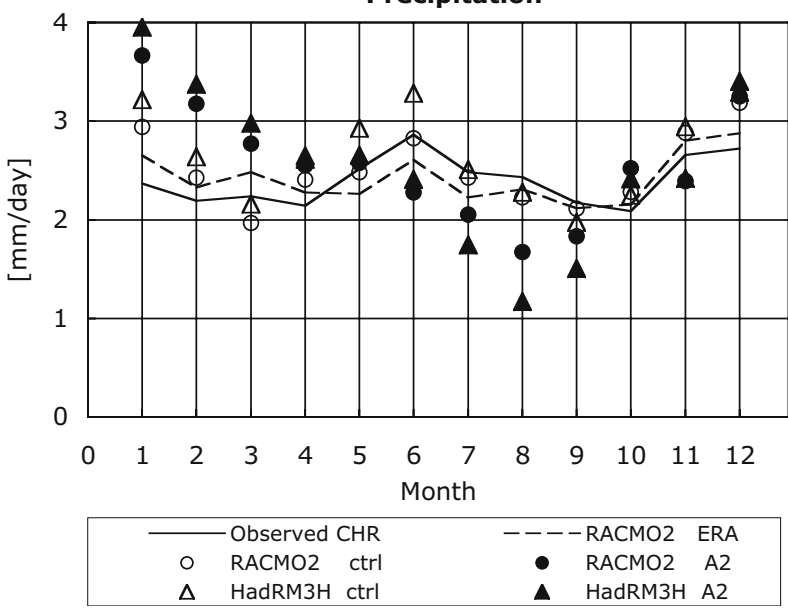


Fig. 7 Cumulative frequency distributions for G-west for winter months

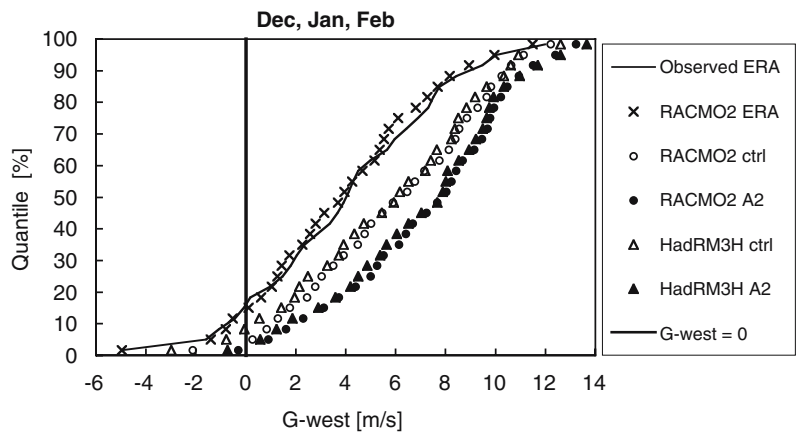

by HadAM3H are quite similar to those produced by HadRM3H. Only the summer months are about $1{ }^{\circ} \mathrm{C}$ cooler and less dry (not shown).

More insight into the origins of biases and changes in the simulations by the two regional models can be obtained by investigating the simulated distributions of $G$-west, temperature and precipitation. This is done in the next section.

Fig. 8 Distributions for winter months. Data points are monthly means. The regression lines are variance conserving and have a length of 4 standard deviations. Upper panel: G-west and temperature for RACMO2. Lower panel: G-west and precipitation for RACMO2
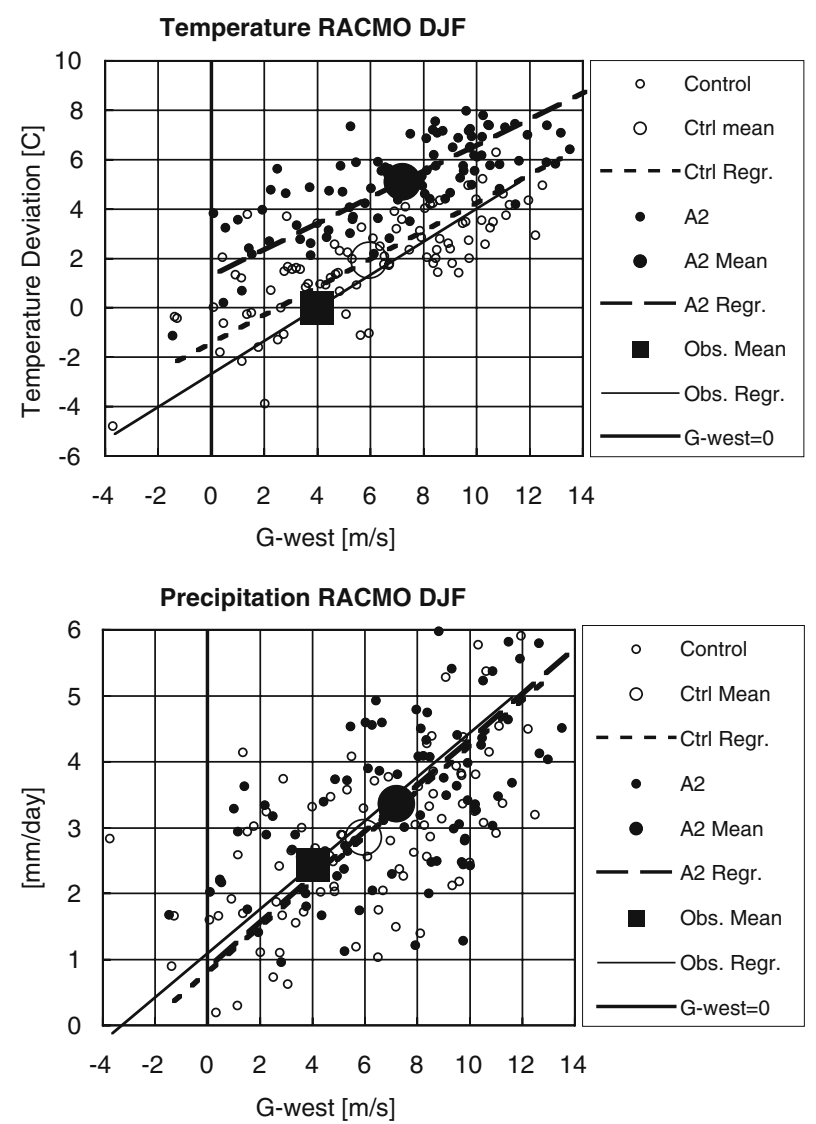


\section{Relations between temperature, precipitation and $G$-west}

\subsection{Relations for winter months}

The frequency distribution of the monthly mean strength of $G$-west is an important indicator for the climate in Central Europe. In Fig. 7, this distribution is shown for winter months (Dec, Jan, Feb), for the observations (ERA-40), for RACMO2-ERA and for the control and A2 simulations by RACMO2 and HadRM3H. The distributions for driving model HadAM3H are very similar to those of the regional models and not shown. We see in the figure that RACMO2-ERA reproduces the observed distribution of $G$-west very well. The control runs of the regional models simulate clearly stronger westerlies, which can be attributed to a bias in the boundary conditions provided by HadAM3H. The A2-senario runs show a further increase in the strength of westerlies. The strong westerlies in the model simulations are accompanied by a lower than observed frequency of months with a mean flow from the east ( $G$-west negative). In the observations this occurs in about $15 \%$ of the months. In the control simulations this is reduced to about $5 \%$, while in the scenario simulations almost no months occur with a mean flow from the east. Since a month with $G$ west $=0$ is made up of about equal portions of days with westerly flow and days with easterly flow, such months have mixed climate conditions, consisting of equal portions of oceanic and continental air masses. Months with strong easterly flow have continental climate characteristics, while months with strong westerly flow exhibit more oceanic climate conditions. This is illustrated in Fig. 8. These figures give scatter plots of temperature deviations and precipitation against $G$-west. Also included are variance conserving regression lines and averages. Indeed, we see that months with easterly flow are cold and dry, while months with strong westerlies are mild and wet. Simulations by HadRM3H and by HadAM3H produce a very similar picture (not shown).

From the data in Fig. 8 we can also estimate the contribution of biases in G-west to biases in simulated temperature and precipitation.

For RACMO this circulation bias leads to a warm bias of about $1^{\circ} \mathrm{C}$ in the control run relative to the observations. Moreover, the frequency of very cold months is greatly reduced by the lack of months with a strong easterly flow. The warming in the scenario run is enhanced by about $0.5^{\circ} \mathrm{C}$ by a further increase of the strength of $G$-west. Very cold months with strong easterlies no longer occur in the scenario run. This affects the slope of the regression lines which is steepest for the observations and less steep for the model simulations.

The precipitation bias related to enhanced westerlies is about $0.5 \mathrm{~mm} /$ day in the control run, which corresponds to $20 \%$ of the observed precipitation. The scenario run shows an increase of precipitation, which seems to be primarily related to the simulated change towards wetter circulations. This indicates that circulation changes in winter are an important cause for regional precipitation changes (Van Ulden and Van Oldenborgh 2006)

These results show that biases and changes in $G$-west play an important role in the simulation of climate and of climate change in winter.

\subsection{Relations for summer months}

In summer, westerly flows bring cool and moist weather to Europe, while easterlies bring warm and dry weather. In the observations, about $15 \%$ of the months is characterised by a mean geostrophic wind from the east (see Fig. 9). The distribution simulated by RACMO2- 
Fig. 9 Cumulative frequency distributions for G-west for summer months

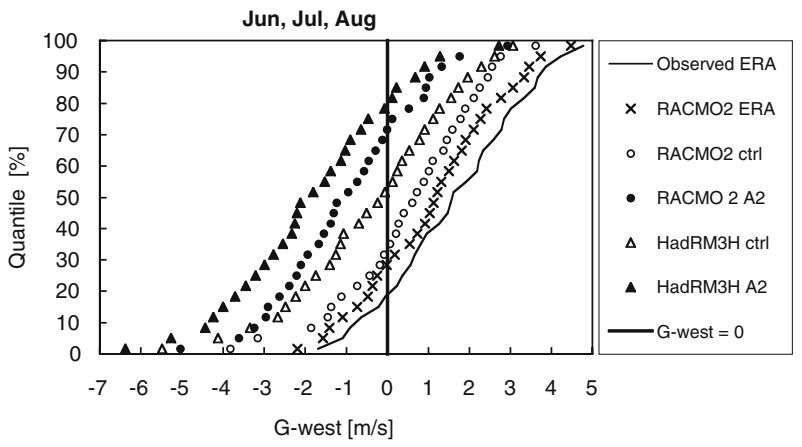

ERA is close to the observations, although the westerlies are slightly weaker than observed and about $20 \%$ of the months has a negative $G$-west. In the control run with RACMO2 the westerlies are slightly weaker than in RACMO2-ERA. The distribution simulated by RACMO2 is close to the distribution simulated by the global model HadAM3H. For HadRM3H the distribution deviates considerably from this, in particular in the negative range of $G$-west, which adds up to about $50 \%$ of the summer months. The lower tail of this distribution consists of months with very strong and persistent easterlies. This behaviour is even more pronounced in the scenario simulations. In the A2-scenario run by HadRM3H $80 \%$ of the summer months have a mean flow from the east. This corresponds to a very continental climate.

In Fig. 10 we show the corresponding simulations of temperature and precipitation. We see the expected relationships: temperature decreases with increasing $G$-west, while precipitation increases with increasing $G$-west. However, the two models show interesting differences. For the control simulation of temperature by RACMO2, the slope of the regression line is almost the same as the observed slope. This implies that the sensitivity of RACMO2 temperatures to variations in $G$-west is similar to the observed sensitivity. In this respect RACMO2 is a realistic model. For HadRM3H the slope of the regression line is about $60 \%$ steeper than observed. For the month of July in the 25 th year of the simulation an anomaly of $11.7 \mathrm{~K}$ is simulated, which is about 8 standard deviations from the mean. Apparently, HadRM3H temperatures are much more sensitive to variations in $G$-west than observed. Probably, this high sensitivity is due to a high sensitivity to summer drying (Seneviratne et al. 2002; Van den Hurk et al. 2005; Lenderink et al. 2007).

For the scenario simulations of temperature, the slope of the regression lines gets much steeper than in the control simulations. This can be understood, because the warming of North Atlantic SST's is much weaker than the warming over land (not shown). Thus, cool extremes, which occur with strong westerlies, change less than warm extremes. Moreover, the warm extremes for strong easterlies are enhanced by soil moisture depletion (Lenderink et al. 2007; Vidale et al. 2007). These extremes are much higher for HadRM3H than for RACMO2.

Drying effects are clearly visible in the simulations of precipitation. In the control runs, the models simulate more than observed precipitation for a given value of $G$-west. This is counter-acted by dryer than observed circulations in the control runs. In the scenario runs, the mean flow is from the east, and precipitation is effectively suppressed, except for conditions with prevailing westerlies. 

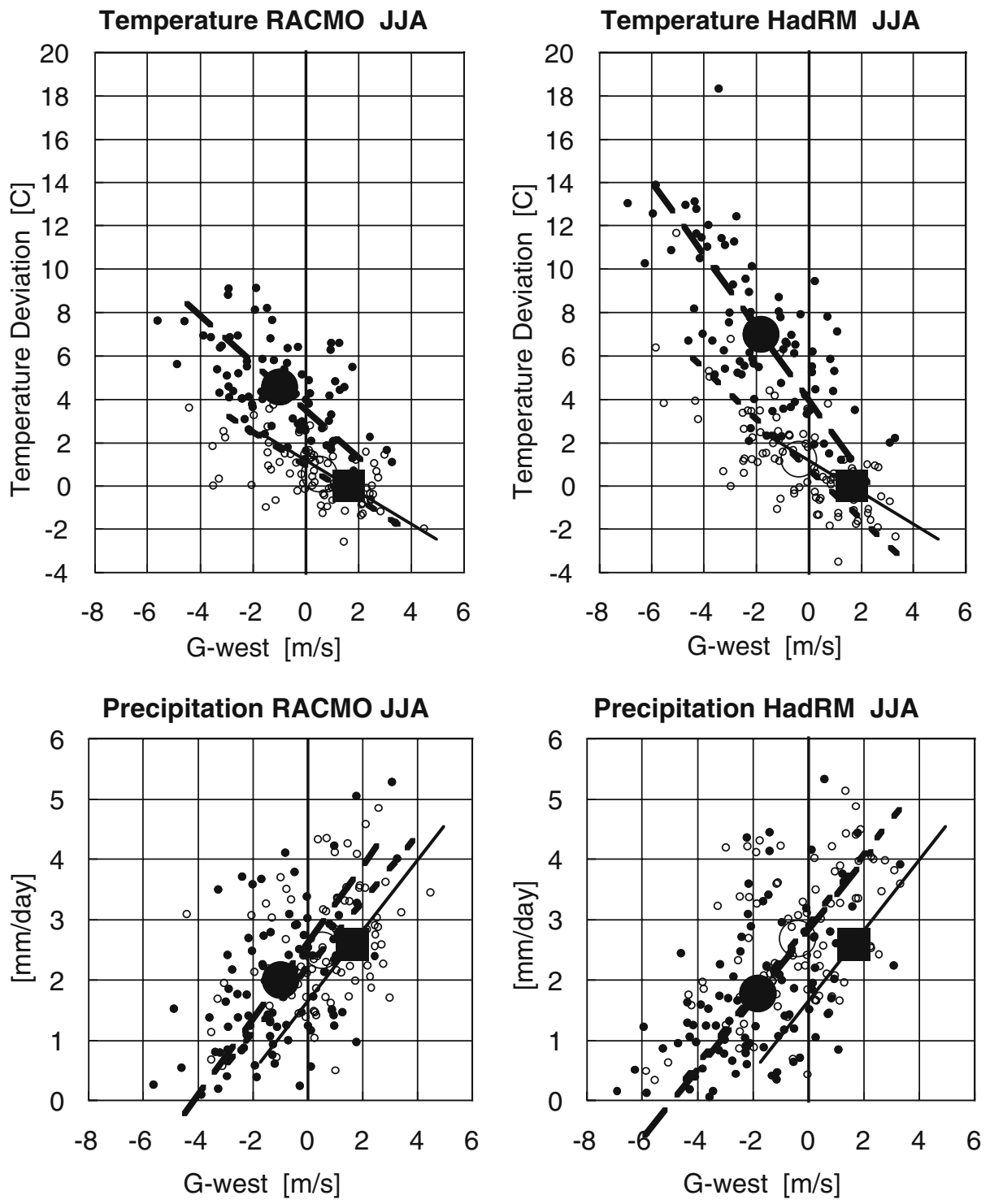

Fig. 10 As Fig. 8, but for summer months. Upper panels: G-west and temperature for RACMO2 and HadRM3H. Lower panels: G-west and precipitation for RACMO2 and HadRM3H

One may wonder why HadRM3H has such a strong bias in the frequency and strength of easterly flows. A possible explanation is the following. Temperatures over Northern Europe are mainly under the influence of westerly flows. Since SST's are prescribed in the same manner for all regional models, temperatures over Northern Europe are more or less fixed by the prescribed SST's, also for the global model HadAM3H. Over the Southern European continent, temperatures are strongly influenced by soil moisture availability. Models with a high sensitivity for summer drying, such as HadRM3H, and to a lesser extent HadAM3H will produce warmer temperatures for easterly flows, due to a lack of evaporative cooling. 
This results in higher temperature contrasts between north and south. In turn this may lead to a northwards displacement of the European extension of the Azores high pressure system, which enhances the strength of the easterlies. In turn, more frequent and stronger easterly flows will bring fewer clouds and enhance soil moisture depletion. This type of interactions between land surface processes and atmospheric circulation has been studied over the southwestern United States by Kanamitsu and Mo (2003). Although the geographic conditions were rather different, this study clearly showed the potential importance of such interactions. and the sensitivity of climate model simulations to the detailed treatment of land surface processes.

A similar mechanism may lead to a further northward shift of the ridge of high pressure over Europe in the A2-scenario simulations, because temperatures over the North Atlantic will rise slower than temperatures over Central and Southern Europe. Such a positive feedback between soil moisture depletion, land temperatures and circulation would make the European climate system over Europe highly non-linear, and very senstive to the details of the treatment of the hydrological cycle in the model. Since many PRUDENCE models have a warm summer bias and a higher than observed temperature variability over Central and Southern Europe (Lenderink et al. 2007), it is likely that the PRUDENCE ensemble as a whole has a warm and dry bias in summer.

\section{Conclusions}

The control simulations by the global model HadAM3H of three geostrophic flow indices for Central Europe are realistic, both with respect to the mean annual cycle and with respect to interannual variability. Nevertheless, we identified a few important shortcomings. The simulated west component of the geostrophic wind is too strong in winter and too weak in summer. This bias cannot be attributed to natural variability.

The regional models, using boundary conditions from HadAM3H, produce rather similar circulation statistics as HadAM3H, in particular in winter. The circulation bias in winter leads to a warmer and wetter than observed climate. There is a lack of persistent eastcirculations and a lack of very cold months. In summer the frequency of persistent eastcirculations is too high, but this bias differs from model to model. The regional model RACMO2, which has realistic summer drying properties, simulates realistic relations between temperature and precipitation on the one hand, and circulation variations on the other hand. HadRM3H, which is quite sensitive to soil moisture depletion, simulates a rather extreme variability in summer temperatures. Moreover this model enhances the easterly circulation bias imported from HadAM3H. This may be related to an enhancement of south-north temperature gradient for easterly flow conditions, due to a strong temperature response to soil moisture depletion over Southern Europe.

The scenario simulations reveal important circulation changes. In winter, more frequent westerlies enhance the warming and produce increased precipitation. In summer, the frequency of easterly flows increases markedly, which leads to more pronounced summer drying and an increase in the frequency of very warm months. The impact of changing summer circulations is rather model dependent. Again, the sensitivity to soil moisture depletion plays a major role. A positive feedback between circulation changes and summer drying may be responsible for this.

Apparently, the role of biases and changes in the atmospheric circulation is important in the simulation of the climate in Central Europe. 


\section{References}

Christensen JH, Christensen OB (2007) A summary of the PRUDENCE model projections of changes in European climate by the end of this century. Clim Change, doi:10.1007/s10584-006-9210-7 (this issue)

Christensen JH, Carter TR, Giorgi F (2002) PRUDENCE employs NEW methods to assess European climate change. EOS 83:147

D’Andrea F, Tibaldi S, Blackburn M, Boer G, Dequé M, Dix MR, Dugas B, Ferranti L, Iwasaki T, Kitoh A, Pope V, Randall D, Roeckner E, Straus D, Stern W, Van den Dool H, Williamson D (1998) Northern Hemisphere atmospheric blocking as simulated by 15 atmospheric general circulation models in the period 1979-1988. Clim Dyn 14:385-407

Déqué M, Rowell DP, Lüthi D, Giorgi F, Christensen JH, Rockel B, Jacob D, Kjellström E, de Castro M, van den Hurk B (2007) An intercomparison of regional climate simulations for Europe: assessing uncertaimties in model projections. Clim Change, doi:10.1007/s10584-006-9228-x (this issue)

Jacob D, Bärring L, Christensen OB, Christensen JH, de Castro M, Dequé M, Giorgi F, Hagemann S, Hirschi M, Jones R, Kjellström E, Lenderink G, Rockel B, Sánchez E, Schär C, Seneviratne SI, Somot S, Van Ulden A, Van den Hurk B (2007) An inter-comparison of regional models for Europe: design of the experiments and model performance. Clim Change, doi:10.1007/s10584-006-9213-4 (this issue)

Jones PD, Davies TD, Lister DH, Slonosky V, Jonsson T, Bärring L, Jonsson P, Maheras P, Kolyva-Machera F, Barriendos M, Martin-Vide J, Rodriguez R, Alcoforado MJ, Wanner H, Pfister C, Luterbacher J, Rickli R, Schuepbach E, Kaas E, Schmith T, Jacobeit J, Beck C (1999) Monthly mean pressure reconstructions for Europe for the 1780-1995 period. Int J Climatol 19:347-364

Jones R, Murphy J, Hassell D, Taylor, R (2001) Ensemble mean changes in simulationof the European climate of 2071-2100 using the new Hadley Centre regional modelling system HadAM3H/HadRM3H. Hadley Centre Report, March, 2001

Jylhä K, Tuomenvirta 'H, Ruosteenoja K (2004) Climate change projections for Finland during the 21st century. Boreal Environ Res 9:127-152

Kanamitsu M, Mo KC (2003) Dynamical effect of land surface processes on summer precipitation over the Southwestern United States. J Climate 16:496-509

Kållberg P, Simmons A, Uppala S, Fuentes M (2004) The ERA-40 Archive. ERA-40 Project Report Series No. 17. ECMWF, Sept. 2004

Lenderink G, van den Hurk B, van Meijgaard E, van Ulden A, Cuijpers H (2003) Simulation of present-day climate in RACMO2: first results and model developments. Technical Report TR-252, Royal Netherlands Meteorological Institute, De Bilt, The Netherlands

Lenderink G, van Ulden A, van den Hurk B, van Meijgaard E (2007) Summertime inter-annual temperature variability in an ensemble of regional model simulations: analysis of the surface energy budget. Clim Change, doi:10.1007/s10584-006-9229-9 (this issue)

New M, Hulme M, Jones P (2000) Representing twentiest century space-time climate variability. Part II: development of a 1901-1996 monthly grids of terrestrial surface climate. J Climate 13:2217-2238

Räisänen J, Hansson U, Ullerstig A, Döscher R, Graham LP, Jones C, Meier HEM, Samuelson P, Willén U (2004) European climate in the late twenty-first century: regional simulations with two driving global models and two forcing scenarios. Clim Dyn 22:13-31

Seneviratne SI, Pal JS, Eltahir EAG, Schär C (2002) Summer dryness in a warmer climate: a process study with a regional climate model. Clim Dyn 20:75-90

Thorpe RP (2005) The impact of changes in atmospheric and land surface physics on the thermohaline circulation response to anthropogenic forcing in HadCM3 and HadCM2. Clim Dyn 24:449-456

Trenberth KE, Paolino DA (1980) The Northern Hemisphere sea-level pressure data set: trends, errors and discontinuities. Mon Weather Rev 108:855-872

Turnpenny JR, Crossley JF, Hulme M, Osborn TJ (2002) Air flow influences on local climate: comparison of a regional climate model with observations over the United Kingdom. Clim Res 20:189-202

Van den Hurk B, Hirschi M, Lenderink G, van Meijgaard E, van Ulden A, Rockel B, Hagemann S, Graham P, Kjellström E, Jones R (2005) Soil control on run-off response to climate change in regional climate model simulations. J Climate 18:3536-3551

Van Oldenborgh GJ, Van Ulden AP (2003) On the relationship between global warming, local warming in the Netherlands and changes in circulation in the 20th century. Int J Climatol 23:1711-1724

Van Ulden AP, Van Oldenborgh GJ (2006) Large-scale atmospheric circulation biases and changes in global climate model simulations and their importance for climate change in Central Europe. Atmos Chem Phys 6:863-881. http://www.atmos-chem-phys.net/6/863/2006/

Vidale PL, Lühti D, Frei C, Schär C (2007) European climate variatiability in a heterogeneous multi-model ensemble. Clim Change, doi:10.1007/s10584-006-9218-z (this issue) 